\title{
Determinan Profitabilitas Bank Perkreditan Rakyat di Kota Palembang Periode 2013-2018
}

\author{
Riri Hanifa \\ Universitas Sjakhyakirti \\ Email: ririhanifa0718@gmail.com \\ Anton Trianto \\ Universitas Sjakhyakirti \\ Email:alkaton79@gmail.com \\ Mahdi Hendrich \\ Universitas Sjakhaykirti \\ Email: mahdihendrich03@gmail.com
}

\begin{abstract}
This study was conducted with the aim to empirically examine the effect of CAR, NPL, BOPO and LDR on profitability (ROA) at the Rural Credit Bank in Palembang for the period 2013-2018. The type of this research is descriptive quantitative The population in the research object is all BPRs contained in Palembang city amounted to 13 BPR while the total sample of 10 BPR. The research sample was taken with a purposive sampling system with the criteria of a BPR whose financial statements were published by the Financial Services Authority in the 2013-2018 period. The method used in this study uses multiple regression analysis with a hypothesis testing tool that is the $\mathrm{t}$ test and the $\mathrm{F}$ test. However, before conducting multiple regression analysis, the classical assumption test is performed first. Through the simultaneous hypothesis test results (Test F) it is known that CAR, BOPO, NPL and LDR have a significant effect on the profitability of BPR (sig 0,000 ). While based on the partial hypothesis test results ( $t$ test) on BPR shows that CAR variable does not influence ROA (sig 0.183), BOPO variable has no effect on ROA (sig 0.114), NPL variable has significant effect on ROA (sig 0.001) and LDR variable also no effect on ROA (sig 0,782 ). Adjusted $R^{2}$ value in the regression model was obtained at 56.1, this indicates that the influence of independent variables on the dependent variable (ROA) was $56.1 \%$ while the remaining $43.9 \%$ was influenced by other factors outside this study.
\end{abstract}

Keywords: Profitability, CAR,BOPO,NPL and LDR

\begin{abstract}
Abstrak
Penelitian ini dilakukan dengan tujuan untuk menguji secara empiris pengaruh CAR,NPL,BOPO dan LDR terhadap profitabilitas (ROA) pada Bank Perkreditan Rakyat di Kota Palembang periode 2013-2018.Jenis penelitian ini adalah deskriptif kuantitatif Populasi pada obyek penelitian adalah seluruh BPR yang terdapat di kota Palembang berjumlah 13 BPR sedangkan jumlah sampel sebanyak 10 BPR. Sampel penelitian diambil dengan sistem Purposive sampling dengan kriteria yaitu BPR yang laporan keuangannya telah dipublikasikan oleh Otoritas Jasa Keuangan pada periode 2013-2018. Metode yang digunakan pada penelitian ini menggunakan analisis regresi berganda dengan alat uji hipotesis yakni uji t dan uji F. Namun, sebelum melakukan analisis regresi berganda terlebeih dahulu dilakukan uji asumsi klasik. Melalui hasil uji hipotesis secara simultan (Uji F) diketahui bahwa CAR,BOPO, NPL dan LDR mempunyai pengaruh yang signifikan terhadap profitabilitas BPR (sig 0,000). Sedangkan berdasarkan hasil uji hipotesis secara parsial (Uji t) pada BPR menunjukkan variabel CAR tidak perpengaruh terhadap ROA (sig 0,183), variabel BOPO tidak berpengaruh terhadap ROA (sig 0,114), variabel NPL berpengaruh signifikan terhadap ROA (sig 0,001) dan variabel LDR juga tidak berpengaruh terhadap ROA (sig 0,782). Nilai Adjusted $\mathrm{R}^{2}$ dalam model regresi diperoleh sebesar 56,1, hal ini menunjukkan bahwa besar penagruh variabel independen terhadap variable dependent (ROA) sebesar 56,1\% Sedangkan sisanya sebesar 43,9\% dipengaruhi oleh faktor lain diluar penelitian ini.
\end{abstract}

Kata kunci: Profitabilitas, CAR,BOPO, NPL dan LDR 


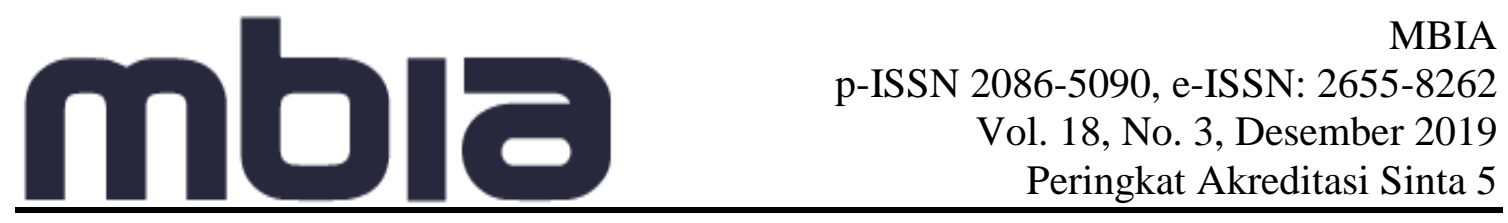

\section{Pendahuluan}

Perekonomian Sumatera Selatan di tahun 2019 diperkirakan masih positif walaupun melambat dibandingkan tahun sebelumnya. Hal ini sejalan dengan proses pemulihan ekonomi global meski dengan tekanan risiko yang meningkat serta pasar komoditas yang bergerak ekspansif akan menjadi penggerak utama ekonomi Provinsi Sumatera Selatan pada tahun 2019. Dari sektor eksternal terdapat beberapa risiko yang perlu diwaspadai seperti tekanan eksternal berupa risiko meningkatnya tekanan perdagangan global seiring kebijakan proteksi Amerika Serikat, kenaikan suku bunga The Fed, kebijakan proteksi dagang negara tujuan ekspor komoditas kelapa sawit, serta fluktuasi harga minyak dunia. (Sumber: Kajian Ekonomi Regional Provinsi Sumatera Selatan Februari - 2019).

Hal ini tentu saja berdampak pada perkembangan ekonomi yang semakin meningkat sehingga menyebabkan banyaknya lembaga keuangan yang berdiri. Salah satu lembaga keuangan yang berperan paling besar serta memiliki peran dalam perekonomian suatu negara adalah Lembaga Keuangan. Lembaga keuangan adalah badan usaha yang kekayannya terutama berbentuk asset keuangan (financial assets) atau tagihan (claims) dibandingkan dengan aset non keuangan (non financial assets).

Menurut UU pokok perbankan nomor 10 tahun 1998, jenis bank menurut Bank Perkreditan Rakyat dan Bank Umum. Bank umum terdiri dari Bank Umum Persero (BUMN Pemerintah), Bank Umum Swasta Nasional (BUSN) devisa, Bank Umum Swasta Nasional (BUSN) non devisa, Bank Pembangunan Daerah (BPD), Bank Campuran (domestik\&Asing) dan Bank Asing. Bank Perkreditan Rakyat adalah bank yang melaksanakan kegiatan usaha secara konvensional atau berdasarkan prinsip syariah yang dalam kegiatannya tidak memberikan jasa dalam lalu lintas pembayaran (UU No.10 tahun 1998). Sebagaimana bank umum, BPR juga dijamin oleh lembaga penjamin simpanan (LPS) selama penempatan dana tersebut sesuai dengan kriteria yang ditentukan oleh LPS. Sebagai perbandingan pada periode 15 Februari sampai dengan 14 Mei 2015 LPS memberikan tingkat bunga penjaminan kepada BPR sebesar 10,25\% sedangkan kepada Bank Umum sebesar 7,75\% untuk uang rupiah dan 1,5\% untuk mata uang asing/valas.

Menurut Peraturan Otoritas Jasa Keuangan (No.20/POJK.03/2014) pasal 1, "Bank Perkreditan Rakyat yang selanjutnya disebut BPR yaitu bank yang melaksanakan kegiatan usaha secara konvensional yang dalam kegiatannya tidak memberikan jasa dalam lalu lintas pembayaran sebagaimana dimaksud dalam Undang-Undang mengenai perbankan".Menurut Bank Indonesia melalui Peraturan Bank Indonesia nomor 15/3/PBI/2013 tentang Transparansi Kondisi Keuangan Bank Perkreditan Rakyat pada pasal 8b yaitu rasio keuangan yang terdiri dari: (1) Kewajiban Penyertaan Modal Minimun, (2) Non Performing Loan (NPL) dan Penyisihan Penghapusan Aktiva Produktif, (3) Return On Asset (ROA), (4) Beban Operasional terhadap Pendapatan Operasional (BOPO), (5) Cash Ratio, (6) Loan to Deposit Ratio (LDR).

Menurut UU N0.7 tahun 1992 tentang perbankan, BPR adalah bank yang hanya menerima simapanan dalam bentuk deposito berjangka, tabungan atau tabungan pada bank lainnya. Dalam menjalankan usaha BPR dilarang 1) menerima simpanan dalam bentuk giro,2)melakukan kegiatan usaha dalam valuta asing, 3) melakukan penyertaan 
modal, 4) melakukan usaha perasuransian. Denga adanya batasan-batasan tersebut maka sumber pendapatan BPR bertumpu pada margin antara bunga kredit dengan biaya bunga simpanan. Dengan adanya keterbatasan SDM,Jaringan dan teknologi berkakibat pada tingginya bungan simpanan yang ditawarkan kepada masyarakat, akibat tingginya bunga simpanan maka bunga kredit yang ditawarkan kepada debitur juga tinggi. Bunga kredit yang tinggi menjadi risiko terhadap pengembalian kredit dari debitur yang pada akhirnya akan berpengaruh terhadap Non Performing Loan.

Peran Bank Perkreditan Rakyat dalam menunjang perekonomian di kota Palembang adalah membantu permodalan dalam bentuk kredit dalam menunjang operasional bisnis para debiturnya. Prosedur yang masih sederhana dan proses yang sangat cepat dalam pencairan kredit menjadi pilihan para usahawan disektor mikro maupun menengah. Semakin banyak jumlah kredit yang disalurkan oleh BPR, semakin tinggi kemampuan bank dalam menghasilkan pendapatan berupa interest margin dari kredit yang disalurkan, mengingat asset yang paling produktif bagi perbankan adalah kredit yang disalurkan kepada para debitur mereka.

Di Kota Palembang sendiri terdapat 13 Bank Perkreditan Rakyat (BPR) yang beroperasi antara lain yaitu : PT. BPR Mitra Central Dana, PT. BPR Sukasada, PT. BPR Tri Gunung Selatan, PT. BPR Multidana Mandiri, PT. BPR MusiArtha Surya, PT. BPR Prabumegah Kencana, PT. BPR Sumatera Selatan, PT. BPR Prima Dana Abadi, PT. BPR Puskopat, PT. BPR Catur Mas dan PT. BPR Ukabima Grazia, PT. BPR Bintang Dana Persada, PT. BPR Palembang. Kesehatan kinerja keuangan perbankan merupakan bagian terpenting bagi lembaga perbankan, baik bagi bank itu sendiri maupun bagi masyarakat. Kepercayaan masyarakat dapat dibangun dengan bentuk transparansi dari lembaga perbankan tersebut baik dari segi laporan keuangan dan keadaan kesehatan bank yang dipublikasikan. Kinerja Bank Perkreditan Rakyat (BPR) di Provinsi Sumatera Selatan dapat dilihat melalui tabel 1.1 dibawah ini :

Tabel 1.1 Rata-rata ROA,CAR,BOPO,LDR dan NPL pada Bank Perkreditan Rakyat Palembang periode 2017-2018

\begin{tabular}{|l|l|l|l|l|l|l|}
\hline Variabel & 2013 & 2014 & 2015 & 2016 & 2017 & 2018 \\
\hline CAR & $20,8 \%$ & $21,7 \%$ & $22 \%$ & $20 \%$ & $22,6 \%$ & $21,1 \%$ \\
\hline BOPO & $77,9 \%$ & $85,8 \%$ & $90,3 \%$ & $96,8 \%$ & $96,1 \%$ & $90 \%$ \\
\hline LDR & $73,7 \%$ & $75,10 \%$ & $70,9 \%$ & $51,9 \%$ & $62,3 \%$ & $69,6 \%$ \\
\hline NPL & $7,7 \%$ & $9 \%$ & $11 \%$ & $13 \%$ & $10,7 \%$ & $4,6 \%$ \\
\hline ROA & $3,9 \%$ & $2,6 \%$ & $1,5 \%$ & $0,8 \%$ & $-1,2 \%$ & $-0,4 \%$ \\
\hline
\end{tabular}

Pada tabel diatas terlihat bahwa pergerakan rata-rata Return on Aseet (ROA) tahunan mengalami fluktuasi dengan trend menurun. Pada periode 2013 sampai dengan 2018 mengalami penurunan setiap tahunnya dari 3,9\% ditahun 2013 sampai menjadi -0,4\% pada tahun 2018. Adanya fenomena pergerakan Capital Adequacy Ratio (CAR) dari tahun 2013 sampai dengan 2018 cendrung mengalami peningkatan, tetapi pergerakan Return on Asset (ROA) mengalami penurunan, hal ini menunjukkan hubungan yang tidak searah sehingga perlu dilakukan penelitian lanjutan. Adanya fenomena pergerakan Non Performing Loan (NPL) dari tahun 2013 sampai dengan 2017 cendurng mengalami 


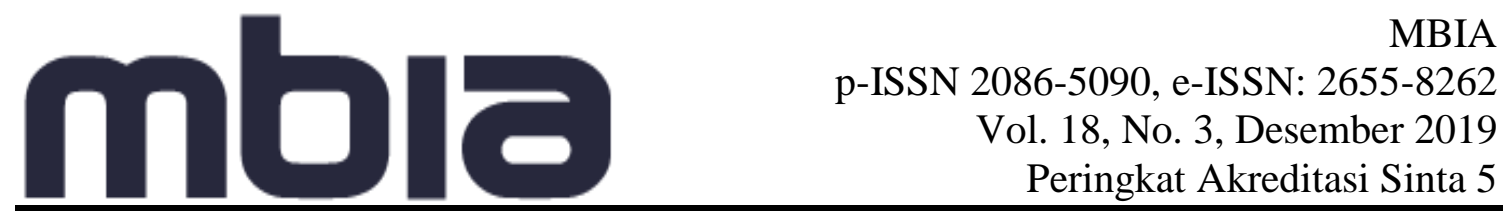

peningkatan, namun pada tahun 2018 mengalami perbaikan signifikan menjadi 4,6\% dari $10,7 \%$ di tahun 2017. Kondisi ini berlawanan dengan nilai ROA ditahun 2018 yang mengalami penurun menjadi- $0,4 \%$, hal ini menunjukkan adanya hubungan yang tidak searah sehingga perlu dilakukan penelitian lanjutan.

Dari hasil penelitian terdahulu terdapat beberapa variabel yang berpengaruh terhadap Return on Asset (ROA). Variabel Capital Adequacy Ratio (CAR) yang diteliti oleh Yusriani (2018),Muh Sabir, M.Ali dan Abd Hamid (2012)Ahmad A (2014), Sri U (2015), Yuliani (2007), Azwir (2006) berpengaruh positif terhadap ROA. Lain halnya dengan Mawardi (2004), Slamet Fajari dan Sunarto (2017),Edhi Satriyo dan M.Syaichu (2013) menunjukkan CAR tidak berpengaruh terhadap ROA, hasil penelitian ini menunjukkan adanya research gap yang perlu adanya penelitian lanjutan. Variabel BOPO yang diteliti oleh Taufik (2014), Yusriani (2018), Risky Diba (2016) menunjukkan adanya pengaruh positif terhadap ROA, sedangkan variabel BOPO yang diteliti oleh Luh E, Nyoman T dan Luh G (2013), Bambang S(2010), Palupi L, Sri U (2015) menunjukkan hasil yang begatif terhadap ROA, hasil penelitian menujukkan adanya research gap dan perlu dilakukan penelitian lanjutan.

Variabel Loan to Deposit Ratio (LDR) yang diteliti oleh Farah M, Marsheilli P (2013), Ahmad (2014), Erna S dan Joko P (2016), Ahmad A (2014) menunjukkan adanya pengaruh positif terhadap ROA. LDR yang diteliti oleh Erna S dan Joko P (2017), Tan S (2011), Slamet Fajari dan Sunarto (2017) menunjukkan tidak ada pengaruh terhadap ROA. Hasil penelitian ini meunjukkan adanya research gap yang perlu adanya penelitian lebih lanjut.

Variabel NPL yang diteliti oleh Slamet Fajari dan Sunarto (2017), Yusriani (2017) dan Tan S (2011) menunjukkan adanya pengaruh positif terhadap ROA. NPL yang diteliti oleh Palupi L, Sri U(2015), Abdul M (2015), Didik P, Bambang S (2013) menunjukkan pengaruh negative terhadap ROA. Penelitian yang dilakukan oleh Edhi Satriyo dan M.Syaichu (2013) menunjukkan bahwa NPL tidak berpengaruh terhadap ROA. Hasil penelitian menunjukkan adanya research gap dan peril dilakukan penelitian lanjutan.

Pada uraian diatas fenomena empiris yaitu mengenai rasio-rasio keuangan BPR mengalami fluktuasi serta ditemukannya research gap memuaskan serta tidak konsisten, perbedaan rasio keuangan serta pengambilan sampel yang berbeda juga menjadi dasar diperlukannya kembali melakukan penelitian mengenai faktor-faktor yang mempengaruhi profitabilitas. Sehingga peneliti merasa perlu untuk melakukan penelitian yang berjudul "Analisis pengaruh Capital Adequency Ratio (CAR), Rasio Biaya Opersional pada Biaya Operasional (BOPO), Non Performing Loan (NPL) dan Loan to Deposit ratio(LDR) terhadap Profitabilitas Bank Perkreditan Rakyat di Kota Palembang Periode 2013 - 2018".

\section{Literature Review dan Pengembangan Hipotesis}

\subsection{Agency Theory}

Hubungan keagenan pada lembaga perbankan sangat kompleks. Pada lembaga perbankan akan melibatkan hubungan pemegang saham dengan manajemen (agen), hubungan bank (pemegang saham) dengan debitur, juga melibatkan hubungan dengan regulator. Dalam 


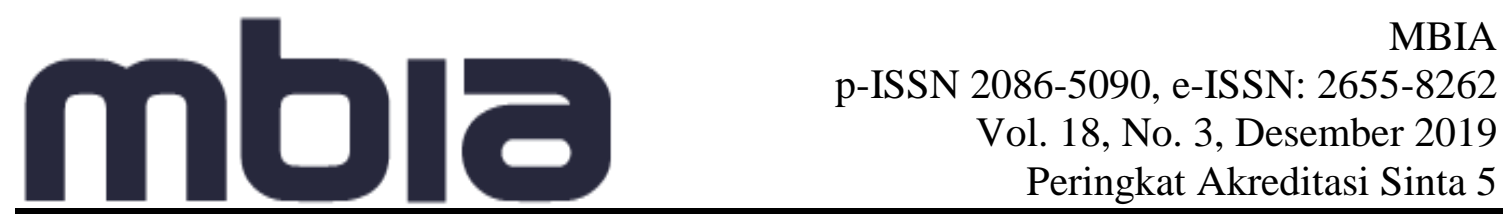

hubungan keagenan manajer sebagai pihak yang memiliki akses lagsung terhadap informasi perusahaan, memiliki asimetris informasi terhadap pihak eksternal perusahaan sperti kreditor dan investor. Untuk itu pengelolaan perusahaan harus diawasi dan dikendalikan untuk emmastikan bahwa pengelolaan dilakukan dengan penuh kepatuhan dengan berbagai peraturan dan ketentuan yang berlaku yang menimbulkan apa yang disebut sebagai agency cost.

\subsection{Signalling Theory}

Menekankan kepada pentingnya informasi yang dikeluarkan oleh perusahaan terhadap keputusan investasi pihak diluar perusahaan. Pengumuman informasi akutansi memberikan signal bahwa perusahaan mempunyai prospek yang baik di masa yang akan datang (good news) sehinnga investor tertarik untuk melakukan perdagangan saham atau para deposan tertarik untuk menambahkan dananya dibank tersebut. Jika suatu perusahaan ingin sahamnya dibeli oleh investor maka perusahaan harus melakukan pengungkapan laporan keuangan secara terbuka dan transparan

\subsection{Bank Financial Fragility}

Dalam teori ini bank tidak menahan atau menyimpan modal apapun. Melainkan mengembalikan modal tersebut kepada masyarakat melalui kredit yang diberikan. Jika bank terlalu gencar dalam penyaluran kredit tersebut maka kemampuan bank untuk liquidity creation tersebut akan menurun. Oleh sebab itu modal bank yang meningkat dapat menghambat likuiditas dan mempunyai hubungan yang negative. Hal ini terjadi karena banyaknya kredit yang diberikan disbanding dengan penyediaan likuiditas pada bank tersebut.

\subsection{Pengaruh CAR terhadap ROA}

CAR mencerminkan modal sendiri perusahaan untuk menghasilkan laba. Semakin besar CAR maka semakin besar kesempatan bank dalam menghasilkan laba karena dengan modal yang besar, manajemen bank sangat leluasa dalam menempatkan dananya kedalam aktivitas investasi yang menguntungkan. Selain itu Modal bank juga dipergunakan untukmenutupi potensi kerugian yang tidak terduga (unexpected loss) dan sebagai cadangan pada saat terjadi krisis perbankan (IBI,2016). Dana tersebut dapat diperoleh dari pemilik bank (pemegang saham) pemerintah, Bank Indonesia dan DPK. Pembentukan dan peningkatan peranan aktiva bank sebagai penghasil keuntungan harus memperhatikan kepentingan stakeholder, dengan demikian bank harus menyediakan modal minimum yang cukup untuk menjamin kepentingan pihak ketiga (Sinungun,2000). Teori ini didukung oleh penelitian Yuliani (2007), Azwir (2006), Mohamad M \& Abdul M (2015), Farah M dan Marshelly P (2013) dan Ahmad A (2014) menguji CAR terhadap ROA menunjukkan hasil yang positif signifikan. Dari hasil penelitian beberapa peneliti sesuai dengan teori yang mendasari bahwa semakin tinggi CAR yang dicapai oleh bank menunjukkan kinerja bank semakin baik sehinnga laba perusahaan semakin meningkat. Dengan kata lain CAR berhubungan positif dengan laba perusahaan dengan demikian dapat dirumuskan hipotesis pertama sebagai berikut:

H1: CAR berpengaruh posotif signifikan terhadap ROA BPR 


\subsection{Pengaruh BOPO terhadap CAR}

BOPO diukur secara kuantitatif dengan menggunakan rasio efisiensi (Bambang Sudiyanto,2010). Malalui rasio ini diukur apakah manajemen bank telah menggunakan semua faktor produksinya dengan efektif dan efisien. BOPO merupakan perbandingan antara total biaya operasional dan total pendapatan operasional. Biaya operasional dihitung berdasarkan penjumlahan dari total beban bunga dan beban operasional lainnya. Sedangkan pendapatan pendapatan operasional merupakan penjumlahan dari total pendapatan biaya. Semakin kecil BOPO menunjukkan semakin efisien bank dalam menjalankan aktivitas usahanya. Bank yang sehat rasio BOPO nya kurang dari 1 sebaliknya bank yang kurang sehat rasio BOPO nya lebih dari 1. Dengan kata lain BOPO berhubungan negative terhadap profitabilitas bank. Teori ini didukung oleh Mohammad M Koswar H\&Abdul M (2015), Yuliani (2007), Slamet Fajari \& Sunarto (2017), Edhi Satryio W \& Muahammad Syaichu (2013) yang menyatakan bahwa BOPO berpengaruh signifikan negative terhadap ROA.Berdasarkan uraian tersebut dapat dirumuskan hipotesis sebagai berikut:

H2: BOPO berpengaruh negative dan signifikan terhadap Profitabilitas (ROA) BPR

\subsection{Pengaruh NPL terhadap ROA}

Non Performing Loan (NPL) mencerminkan risiko pembiayaan, semakin tinggi rasio ini menujukkan kualitas pembiayaan BPR semakin buruk. Pengelolaan pembiayaan sangat diperlukan oleh bank, mengingat fungsi pembiayaan sebagai penyumbang pendapatan terbesar bagi Perbankan. NPL merupakan perbandingan antara kredit bermasalah terhadap total kredit (Didik P dan Bambang S,2013). Kredit bermasalah sebenarnya bersifat kasuasitas, yang artinya msalah yang ada pada satu debitur akan berbeda dengan debitur lainnya (Slamet F\&Sunarto, 2017). Bank dapat mendeteksi dari variabel-variabel dalam penempatan kolektibilitas yang didasarkan pada kriteria tunggakan utang pokok dan bunga dan iverdraft. Suatu kredit dikatakan bermasalah bila memenuhi kriteria kolektibilitasnkredit 2\%dan 4\% (Taswan, 2010). Bertambahnya NPL akan mengakibatkan hilangnya kesempatan untuk memperoleh pendapatan dari pembiayaan yang diberikan sehingga mempengaruhi perolehan laba dan perpengaruh terhadap penurunan ROA. Teori ini didukung oleh penelitian Zainudin dan Jogiyanto (1999), Didit Purwako dan Bambang S (2013), Muh Sabir,M Ali \&Abdul Hamid, 2012). Berdasarkan uraian diatas dapat dirumuskan hipotesis sebagai berikut:

H3: NPL berpengaruh negative dan signifikan terhadap ROA BPR.

\subsection{Pengaruh LDR terhadap ROA}

Loan to Deposit Ratio (LDR) merupakan ukuran likuiditas yang mengukur besarnya dana ditempatkan dalam bentuk kredit yang berasal dari dana yang dikumpulkan oleh bank terutama dana yang berasal dari masyarakat. LDR menunjukkan tingkat kemampuan bank dalam membayar kembali penarikan dana yang dilakukan oleh deposan dengan mengandalkan kredit yang diberikan sebagai sumber likuiditasnya (Dendawaijaya,2009). LDR menunjukkan tingkat kemampuan bank dalam menyalurkan dana pihak ketiga yang dihimpun bank. Besar kecilnya rasio LDR akan mempengaruhi profitabilitas bank tersebut. LDR dihitung dengan membandingkan kredit dengan dana pihak ketiga dimana kredit yang digunakan merupakan total kredit yang diberikan kepada pihak ketiga dan tidak termasuk kredit yang diberikan kepada pihak lain. Sedangkan dana pihka ketiga merupakan giro, tabungan dan deposito yang tidak termasuk antar bank (Yusriani,2018). 
Hasil penelitian Mohammmad M, Koswar\&Abdul (2015), Bambang S (2010),Ahmad (2014), Yusriani (2018) yang meniliti hubungan LDR terhadap ROA menujukkan hasil yang positif dan signifikan. Berdasarkan uraian diatas dapat dirumuskan hipotesis keempat adalah sebagai berikut:

H4: Loan to Deposit Ratio berpengaruh positif signifikan terhadap ROA BPR.

Berdasarkan lamdasan teori dan penellitian-penelitian empiris terdahulu diatas, mengenai berbagai hubungan antara variabel independen dan variabel dependen maka dapat digambarkan kerangka pemikiran teoritis adalah sebagai berikut:

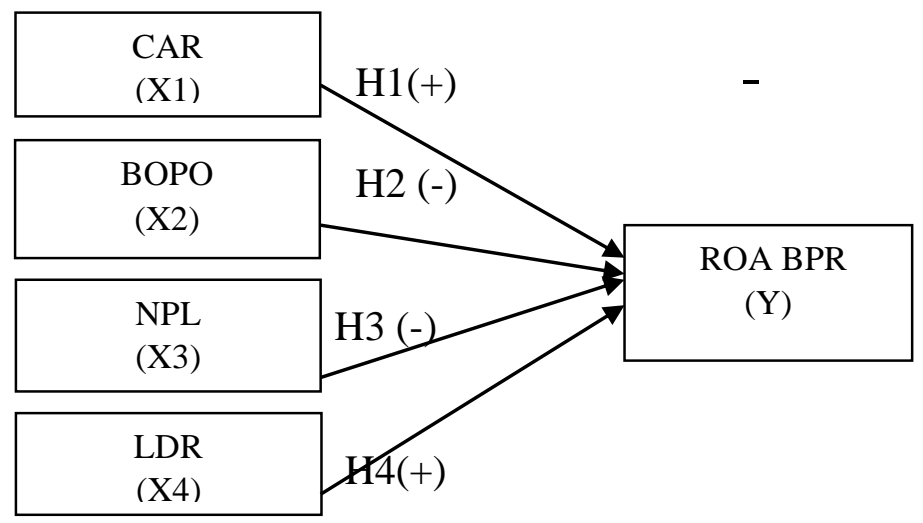

Sumber: Bambang S (2010), Yuliani (2007),Yusriani (2018), Slamet Fajari\&Sunarto (2017).

\section{Metodologi Penelitian}

\subsection{Jenis Data dan Sumber Data}

Jenis data yang digunakan dalam penelitian ini adalah data sekunder. Data berupa rasio rasio keuangan Bank Pembangunan Daerah di Palembang periode 2013-2017 yang telah diaudit dan kemudian dipublikasikan dan diperoleh dari www.bi.go.id dan www.ojk.co.id.

\subsection{Populasi}

Populasi atau universe adalah sebuah wilayah atau tempat obyek/subyek yang diteliti,baik orang, benda, kejadian, nilai maupun yang hal-hal lain yang memiliki kuantitasdan karakteristik tertentu untuk mendapatkan sebuah informasi (Edi R,2016). Populasi yang digunakan dalam penelitian ini adalah Bank Perkreditan Rakyat yg bedomosili di kota Palembang yang berjumlah 13 BPR terdiri dari : PT. BPR Mitra Central Dana, PT. BPR Sukasada, PT. BPR Tri Gunung Selatan, PT. BPR Multidana Mandiri, PT. BPR MusiArtha Surya, PT. BPR Prabumegah Kencana, PT. BPR Sumatera Selatan, PT. BPR Prima Dana Abadi, PT. BPR Puskopat, PT. BPR Ukabima Grazia.

\subsection{Sampel}

Untuk pengambilan sampel ini dilakukan dengan metode purposive sampling yaitu sampel ditarik sejumlah tertentu dari populasi BPR dengan menggunakan pertimbangan atau kriteria tertentu (Sugiyono, 2016). Kriteria sampel dalam penelitian ini adalah sebagai berikut:

1. Laporan Keuangan yang dipublikasin lengkap periode tahun 2013-2018. 


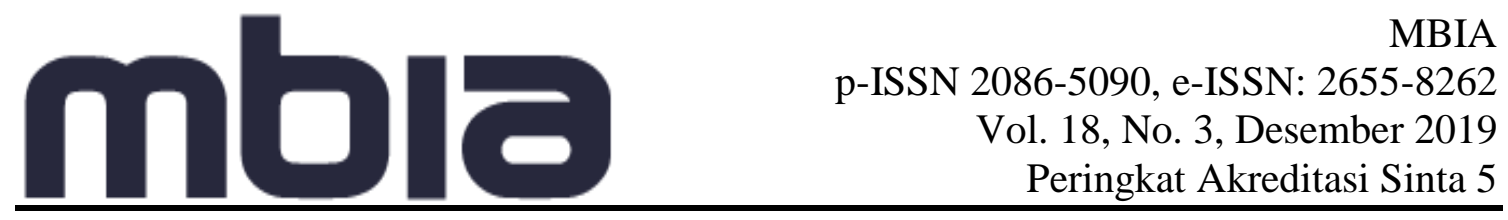

2. Rasio-rasio indikator lengkap periode tahun 2013-2

Dari metode purposive sampling sebanyak 10 BPR yang memenuhi kriteria diatas, yaitu: PT. BPR Mitra Central Dana, PT. BPR Sukasada, PT. BPR Tri Gunung Selatan, PT. BPR Multidana Mandiri, PT. BPR MusiArtha Surya, PT. BPR Prabumegah Kencana, PT. BPR Sumatera Selatan, PT. BPR Prima Dana Abadi, PT. BPR Puskopat, PT. BPR Catur Mas dan PT. BPR Ukabima Grazia, PT. BPR Bintang Dana Persada, PT. BPR Palembang.

\subsection{Variabel Dependen}

Variabel dependen adalah tipe variabel yang dijelaskan atau dipengaruhi oleh variebel Independen (Supomo,1999). Dalam penelitian ini variebel dependen adalah profitabilitas yang diukur dengan Return on Asset (ROA)

\subsection{Variabel Independen}

Variabel Independen adalah tipe variabel yang menjelaskan atau mempengaruhi variabel yang lain (Supomo,1999). Variabel-variabel independen yang akan diuji dalam penelitian ini adalah CAR,BOPO,NPL dan LDR

\subsection{Metode Penelitian}

Analisis data yang dilakukan adalah analisis kuatitatif yang dinyatakan dengan angkaangka dan perhitungannya menggunkana metode statistic yang dibantu dengan program SPSS. Analisis data yang digunakan dalam penelitian ini yaitu pengujian asumsi klasik, analisis regresi berganda dan uji hipotesis. Adapum model dasar dari regresi linear berganda dari penelitian ini dapat dirumuskan sebagai berikut:

$\mathrm{Y}=\mathrm{a}+\mathrm{b} 1 \mathrm{X} 1+\mathrm{b} 2 \mathrm{X} 2+\mathrm{b} 3 \mathrm{X} 3+\mathrm{b} 4 \mathrm{X} 4+\mathrm{e}$

Keterangan:

Y

a

b1-b4

$\mathrm{x} 1$

$\mathrm{x} 2$

$\mathrm{x} 3$

$\mathrm{x} 4$

e
$=$ Variabel Independen (ROA)

$=$ Konstanta

$=$ Koefisien regresi variabel independen

$=$ CAR (Capital Adequancy Ratio)

$=$ BOPO (Biaya Operasional perPendapatan Operasional)

$=$ NPL (Non Performing Loan)

$=\mathrm{LDR}$ (Loan to Deposit Ratio)

$=$ standard error

\section{Hasil dan Pembahasan}

4.1 Uji F Statistik

ANOVA $^{\mathrm{a}}$

\begin{tabular}{lll|l|l|l|l} 
Model & & Sum of Squares & df & Mean Square & F & Sig. \\
\hline 1 & Regression & 1150.850 & 4 & 287.712 & 17.237 & $.000^{\mathrm{b}}$ \\
\cline { 2 - 8 } & Residual & 901.320 & 54 & 16.691 & & \\
\cline { 2 - 7 } & Total & 2052.169 & 58 & & & \\
\hline
\end{tabular}

a. Dependent Variable: ROA

b. Predictors: (Constant), Lag1_NPL, Lag1_LDR, Lag1_BOPO, Lag1_CAR 
Berdasarkan perhitugan dengan F-test dalam tabel diatas diperoleh nilai F-hitung sebesar 17,237 dengan nilai signifikansi sebesar 0,000, Dengan demikian dapat disimpulkan bahwa terdapat pengaruh yang signifikan dari variabel CAR, BOPO, NPL dan LDR terhadap ROA secara simultan.

\subsection{Regresi Linear Berganda}

Dengan regresi linear berganda dapat diperoleh gambaran menyeluruh mengenai hubungan antara mengenai hubungan antara variabel. Variabel dependen yang digunakan pada penelitian ini adalah ROA dan variabel independennya adalah CAR,BOPO.NPL dan LDR.

\begin{tabular}{|c|c|c|c|c|c|c|c|c|}
\hline \multirow[b]{2}{*}{ Model } & & \multicolumn{2}{|c|}{ Unstandardized Coefficients } & \multirow{2}{*}{$\begin{array}{l}\text { Standardized } \\
\text { Coefficients } \\
\text { Beta }\end{array}$} & \multirow[b]{2}{*}{$\mathrm{t}$} & \multirow[b]{2}{*}{ Sig. } & \multicolumn{2}{|c|}{ Collinearity Statistics } \\
\hline & & $\mathrm{B}$ & Std. Error & & & & Tolerance & VIF \\
\hline \multirow[t]{5}{*}{1} & (Constant) & 11.926 & 3.963 & & 3.009 & .004 & & \\
\hline & Lag1_CAR & -.158 & .117 & -.191 & -1.348 & .183 & .404 & 2.475 \\
\hline & Lag1_BOPO & -.054 & .034 & -.182 & -1.607 & .114 & .635 & 1.574 \\
\hline & Lag1_LDR & .010 & .035 & .030 & .278 & .782 & .718 & 1.394 \\
\hline & Lag1_NPL & -.326 & .093 & -.486 & -3.507 & .001 & .424 & 2.357 \\
\hline
\end{tabular}

a. Dependent Variable: ROA

Berdasarkan tabel diatas diperoleh persamaan regresi berganda sebagai berikut:

$\mathrm{ROA}=11,926-0,158 \mathrm{CAR}-0,054 \mathrm{BOPO}-0,326 \mathrm{NPL}+0,010 \mathrm{LDR}+\mathrm{e}$

\subsection{Pengujian Hipotesis (uji t)}

Pengujian hipotesis ini dilakukan untuk melihat hubungan antara variabel dependen dengan variabel independen. Uji $t$ dilakukan untuk mengetahui hubungan CAR,BOPO,LDR dan NPL secara parsial terhadap ROA. Pada tabel diatas dapat kita lihat pengaruh secara parsial dari keempat variabel dependen. Hasil pengujian dari model regresi yang ditunjukkan oleh tabel diatas adalah sebagai berikut:

1. Hipotesis 1 penelitian ini menghipotesiskan adanya pengaruh positif CAR terhadap ROA. Hasil pengujian hipotesis 1 menunjukkan nilai t hitung sebesar 0,191 dengan signifikansi sebesar 0,183 ( $p>0,05$ ). Hal ini menujukkan bahwa CAR memiliki pengaruh negatif terhadap ROA. Dengan demikian hipotesis 1 ditolak.

2. Hipotesis 2 penelitian ini menghipotesiskan adanya pengaruh negatif BOPO terhadap ROA. Hasil pengujian hipotesis 2 menunjukkan nilai t sebesar $-0,182$ dengan signifikansi sebesar 0,114 ( $>$ >0,05). Hasil negatif ini menunjukkan bahwa semakin tinggi BOPO akan menurunkan tingkat profitabilitas bank yang diproksikan dengan ROA. Hal ini berarti bahwa BOPO tidak memiliki pengaruh yang signifikan terhadap ROA. Dengan demikian hipotesis 2 ditolak.

3. Hipotesis 3 penelitian ini menghipotesiskan adanya pengaruh negatif NPL terhadap ROA. Hasil pengujian hipotesis 2 menunjukkan nilai t sebesar -0,486 dengan signifikansi sebesar 0,001 ( $\mathrm{p}<0,05)$. Hal ini berarti bahwa NPL memiliki pengaruh yang signifikan negatif terhadap ROA. Dengan demikian hipotesis 3 diterima.

4. Hipotesi 4 penelitian ini menghipotesiskan adanya pengaruh positif LDR terhadap ROA. Hasil pengujian hipotesis menunjukkan nila t hitung sebesar 0,278 dengan 


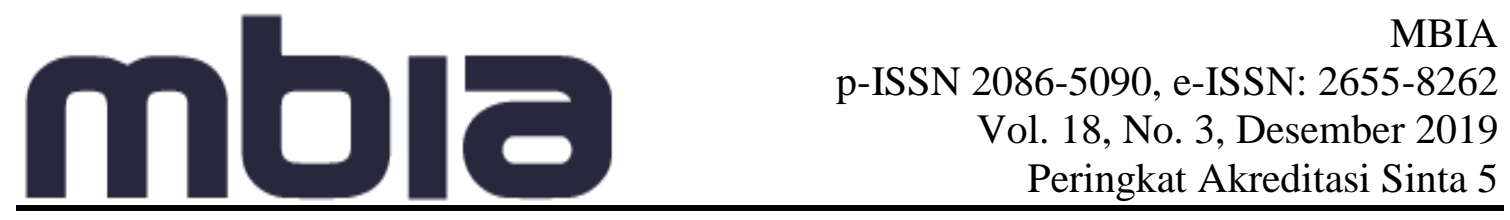

signifikansi sebesar 0,782 ( $\mathrm{p}>0,05)$. Hal ini berarti bahwa LDR tidak memiliki pengaruh signifikan terhadap ROA. Dengan demikian hipotesis 4 ditolak.

\subsection{Koefisien Determinasi}

Koefisien determinasi ini berfungsi untuk melihat seberapa jauh kemampuan model dalam menrangkan variasi variabel dependen. Semakin angka koefisien determinasi mendekati angka 1 maka pengaruh variabel independen terhadap variabel dependen semakin kuat, yang berarti variabel-variabel independen memberikan hamper semua informasi yang dibutuhkan untuk memprediksi variasi variabel dependen. Lalu sebaliknya semakin kecil nilai koefisien determinasi maka kemampuan variabel independen dalam menjelaskan variabel dependen terbatas.

\begin{tabular}{|c|c|c|c|c|c|}
\hline Model & $\mathrm{R}$ & R Square & Adjusted R Square & $\begin{array}{l}\text { Std. Error of the } \\
\text { Estimate }\end{array}$ & Durbin-Watson \\
\hline 1 & $.749^{\mathrm{a}}$ & .561 & .528 & 4.085 & 1.730 \\
\hline
\end{tabular}

Dari tabel diatas diketahui bahwa keempat variabel CAR,BOPO,LDR dan NPL terhadap variabel ROA yang dinyatakan dengan nilai adjusted R square sebesar 0,561 atau 56,1\%. Hal ini berarti $56,1 \%$ variasi ROA bisa dijelaskan oleh keempat variabel independen. Sedangkan sisanya sebesar 43,9\% dijelaskan oleh variabel lain diluar penelitian ini.

\subsection{Uji Asumsi Klasik}

\section{Uji Normalitas}

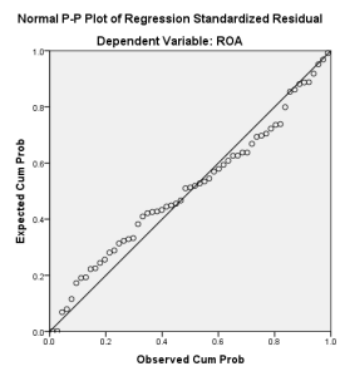

Berdasarkan grafik Normal P-P Plot, setelah dilakukan transformasi data terlihat bahwa titik-titik berada di sekitar garis diagonal. Dengan demikian dapat dikatakn bahwa data telah terdistibusi dengan normal sehingga asumsi normalitas terpenuhi.

Uji Multikolinearitas

Untuk mendeteksi apakah model regresi kita mengalami multikolinieritas, dapat diperiksa menggunakan VIF. VIF merupakan singkatan dari Variance Inflation Factor. Nilai VIF > 10 berarti telah terjadi multikolinieritas yang serius di dalam model regresi kita (Gujarati, D. 1991. Ekonometrika Dasar. Penerbit Erlangga. Jakarta). Sementara menurut Santoso 
(Santoso, Singgih. 2017. Menguasai Statistik dengan SPSS 24. Elex Media Komputindo. Jakarta) Suatu model regresi dikatakan bebas dari multikolinearitas jika nilai Tolerance mendekati angka 1. Nilai VIF pada output regresi terdapat pada tabel Coefficients. Berikut tabel yang berisi ringkasan nilai VIF dan Tolerance yang diambil dari output hasil regresi.

\begin{tabular}{|l|l|l|}
\hline Variabel Bebas & Tolerance & VIF \\
\hline Lag1_CAR & .404 & 2.475 \\
\hline Lag1_BOPO & .635 & 1.574 \\
\hline Lag1_LDR & .718 & 1.394 \\
\hline Lag1_NPL & .424 & 2.357 \\
\hline
\end{tabular}

Berdasarkan tabel di atas, seluruh nilai Tolerance pada variabel bebas tidak ada yang > 1, sedangkan nilai VIF-nya tidak > 10. Dengan demikian dapat dikatakn bahwa model regresi terbebas dari multikolineritas.

Uji Heteroskedastisitas

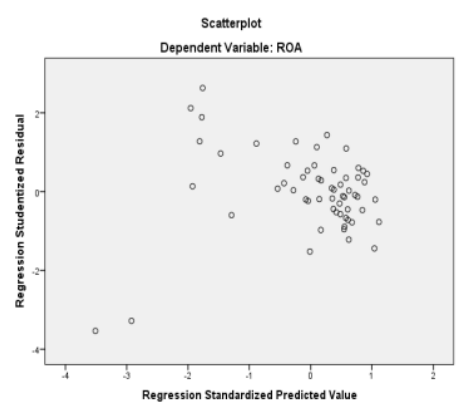

Berdasarkan gambar di atas, terlihat titik-titk tersebar merata di antara titik 0 dan tidak membentuk pola tertentu. Dengan demikian dapat disimpulkan bahwa tidak terjadi heterokedastisitas dan asumsi hemokedastisitas terpenuhi.

Autokorelasi

Berdasakan hasil regresi didapati nilai Durbin-Watson (DW) adalah 1,730 yang terdapat pada tabel Model Summary, sedangkan berdasarkan tabel statistik Durbin-Watson dengan nilai probabilita 0,05 , jumlah $\mathrm{n}$ sebanyak 60 , dan jumlah $\mathrm{k}$ sebanyak 4 , didapati nilai $\mathrm{dl}=$ 1.4443 serta nilai $\mathrm{du}=1.7274$. Dengan angka yang demikian maka pengujian autokorelasi mencapai kriteria du(1.7274)< DW $(1,730)<4-\mathrm{du}(4-1.7274)$ sehingga dapat disimpulkan model regresi tidak mengalami masalah autokorelasi 


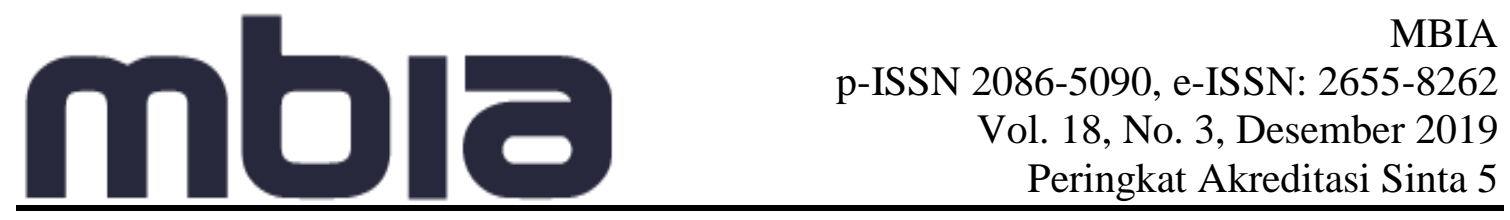

4.6 Pembahasan

Analisis Statistik Deskriptif

Descriptive Statistics

\begin{tabular}{ll|l|l|l|l} 
& $\mathrm{N}$ & Minimum & Maximum & Mean & Std. Deviation \\
\hline CAR & 60 & 15 & 45 & 21.42 & 7.158 \\
\hline BOPO & 60 & 61 & 157 & 89.68 & 19.791 \\
\hline LDR & 60 & 23 & 94 & 70.07 & 17.870 \\
\hline NPL & 60 & 0 & 41 & 9.87 & 8.779 \\
\hline ROA & 60 & -27 & 8 & 1.13 & 5.899 \\
\hline Valid N (listwise) & 60 & & & & \\
\hline
\end{tabular}

Dari tabel diatas menunjukkan bahwa jumlah observasi atau jumlah penagmatan pada bank perkreditan rakyat sebanyak 80 data, hal ini diperoleh dari 10 BPR untuk 6 tahun periode keuangan. Berdasarkan hasil perhitungan didapatkan bahwa nilai minimum $15 \%$ dan maksimum CAR sebesar 45\%. Hal ini menunjukkan bahwa CAR BPR sudah memenuhi standar yang ditetapkan Bank Indonesia ,yaitu minimal 8\%. Rata-rata nilai CAR dari BPR adalah 21,42\%. Standar deviasi sebesar 7,158 memiliki arti bahwa penyimpangan baku dari nilai rata-rata adalah sebesar 7,158\%.

BOPO yang diperoleh menunjukkan nilai minimumnya adalah $61 \%$ dan nilai maksimumnya adalah $157 \%$. Berdasarkan standar Bank Indonesia besarnya nilai BOPO yang normal adalah 94\%-96\%. Hal ini berarti ada BPR yang kurang efisien dalam mengelola biaya opearasionalnya. Lalu untuk rata-ratanya adalah $89,68 \%$. Hal ini secara keseluruhan BPR kurang efisien dalam mengelola operasionalnya. Nilai BOPO terendah dimiliki oleh BPR Multi Dana Mandiri pada tahun 2013, lalu nilai tertinggi pada BPR Musi Artha Surya pada tahun 2017.

Variabel NPL untuk BPR mempunyai nilai minimum sebesar $0 \%$ dan nilai tertinggi sebesar $41 \%$. Berdasarkan standar Bank Indonesia NPL yang normal adalah 5\%. Nilai terendah ada pada BPR Prabu Megah Kencana pada tahun 2017, ini menunjukkan pada tahun tersebut BPR dapat mengelola kredit yang disalurkan kepada debitur. Nilai tertinggi ada pada BPR Sumatera Selatan, rata -rata variabel NPL adalah 9,87\%, ini menunjukkan bahwa secara keseluruhan BPR di kota Palembang belum mampu mengelola penyaluran kredit yang diberikankepada debitur. Standa deviasi sebesar 8,799 memiliki arti bahwa penyimpangan baku dari nilai rata-rata adalah sebesar 8,799\%.

LDR untuk BPR selama periode 2013 sampai dengan tahun 2018 memiliki nilai terendah sebesar 23\% dan nilai tertinggi sebesar 94\%. Berdasarkan standar Bank Indonesia LDR yang normal adalah berada diantara $80 \%-110 \%$. Nilai terendah ada pada BPR Mitra Central Dana pada tahun 2017. Nilai tertinggi ada pada BPR Ukabima Grazia pada tahun 2013. Nilai rata rata BPR sebesar 70,7\% ini berarti BPR belum mampu mengelola penyaluran kredit dan dana pihak ketiganya, sementara nilai standar deviasi diperoleh sebesar $17,870 \%$.

Variabel ROA yang diperoleh menujukkan nilai minimumnya adalah sebesar -27\% . Nilai ini dimiliki oleh BPR Sumatera Selatan pada tahun 2017. Standar nilai profitabilitas dari Bank Indonesia adalah sebesar $>1,5 \%$. Nilai ROA negatif disebabkan bahwa perusahaan 


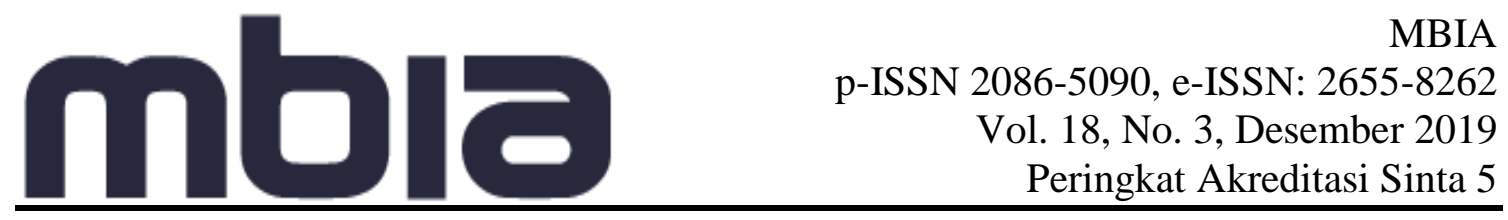

dalam kondisi negatif atau rugi, hal ini menunjukkan kemampuan dari modal yang diinvestasikan secara keseluruhan belum mampu untuk mengahsilkan laba. Nilai maksimum BPR sebesar 8\%. Nilai tertinggi ini dimiliki oleh BPR Ukabima Grazia pada tahun 2017. Lalu untuk rata-rata yang diperoleh pada masa penelitian yakni 2013 sampai 2018 adalah 1,13\% lalu untuk standar deviasinya sebesar 5,899\%.

\section{Pengaruh CAR terhadap ROA}

Dari hasil pengujian hipotesis 1 didapatkan bahwa CAR tidak memiliki pengaruh yang signifikan terhadap ROA. Hasil penilitian ini mengindikasikan bahwa besar kecilnya kecukupan modal Bank Perkreditan Rakyat di kota Palembang belum tentu mempengaruhi kinerja profitabilitas bank tersebut. Bank yang memiliki modal besar belum tentu dapat menggunakan modalnya secara efektif dan efisien untuk menghasilkan laba. Hal ini disebabkan oleh sikap kehati-hatian pihak BPR dalam menyalurkan kredit dikarenakan tinggi rasio NPL yang mengakibatkan keuntungan tidak maksimal, sehingga masyarakat deposan masih tetap mempercayakan dananya di bank tersebut. Selain itu hal ini disebabkan oleh fenomena data laporan keuangan BPR pada waktu periode penelitian CAR mengalami kenaikan tetapi ROA mengalami penurunan. Hasil penelitian ini didukung oleh penelitian dari Taufik Zulfikar (2012), Didik P dan Bambang (2013), Slamet Fajari dan Sunarto (2017), Mawardi (2004), Edhi Satriyo dan M Syaichu (2013).

\section{Pengaruh BOPO terhadap ROA}

Hipotesis kedua menyatakan bahwa Operation Efficiency (BOPO) berpengaruh negatif dan signifikan terhadap ROA. BOPO diukur secara kuantitatif dengan menggunakan rasio efisiensi (Bambang Sudiyanto, 2010). Melalui rasio ini diukur apakah manajemen bank telah menggunakan semua faktor produksinya dengan efektif dan efisien. Dari hasil penelitian ini BOPO tidak memiliki pengaruh terhadap kinerja keuangan BPR dipalembang namun memiliki arah yang negatif sesuai dengan teori yang ada. BOPO memiliki nilai koefisien regresi $-0,054$ dan nilai signifikansi sebesar 0,114 sehingga BOPO tidak berpengaruh terhadap ROA. BOPO tidak berpengaruh karena bank perkreditan rakyat di kota Palembang cenderung untuk menginvestsikan dananya dengan hati-hati dan lebih menekankan pada survival bank sehingga tidak berpengaruh banyak terhadap profitabilitas bank. Jadi apabila nilai BOPO tinggi otomatis nilai biaya operasional bank tersebut besar dan pendapatannya rendah. Besarnya BOPO dapat disebabkan juga dari tingginya biaya dana yang dihimpun dan rendahnya pendapatan bunga dari penyaluran kredit. Bank yang sehat ketentuan dari BI harus memiliki BOPO 93,52\% (Surat Edaran Bank Indonesia No.6/23/DPNP tanggal 31 Mei 2004). Jika sebuah bank memiliki BOPO lebih dari ketentuan BI maka bank tersebut kategori tidak sehat dan tidak efisien. Hasil ini konsisten dengan penelitian Yonira (2014), Ponco (2008), Siti Sintiya (2018) dan Eng (2013) yang menyatakan BOPO bahwa variabel BOPO tidak berpengaruh terhadap ROA.

\section{Pengaruh NPL terhadap ROA}

Hasil pengujian hipotesis ketiga mendapatkan bahwa NPLHasil penelitian ini menunjukkan bahwa NPL memiliki pengaruh negatif dan signifikan terhadap ROA pada Bank Perkreditan Rakyat di Kota Palembang periode tahun 2013-2018. Hasil penelitian yang menunjukkan pengaruh negatif ini memiliki arti, apabila terjadi peningkatan terhadap NPL maka profitabilitasnya (ROA) mengalami penurunan sehingga hipotesis 


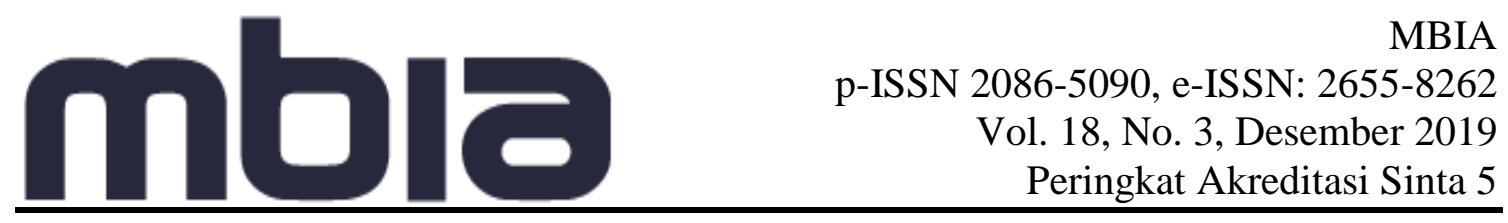

kedua diterima. Hasil penelitian ini sejalan dengan teori yang menyatakan bahwa kredit bermasalah akan berakibat pada kerugian bank karena tidak diterimanya kembali dana yang sudah disalurkan beserta pendapatan bunganya yang berakibat pada penurunan pendapatan secara total (Ismail, 2014). Ketika ada kegagalan debitur untuk membayar, itu akan menurunkan profitabilitas bank (Kristianti dan Yovin, 2016). Maka apabila bank memiliki jumlah pembiayaan macet yang tinngi, maka bank akan berusaha terlebih dahulu mengevaluasi kinerja mereka dengan menghentikan penyaluran kredit hingga NPF mencapai batas normal sesuai dengan peraturan Bank Indonesia yaitu maksimal sebesar 5\%. Hasil penelitian ini didukung oleh penelitian yang dilakukan oleh Pratiwi dan Wiagustini (2015) dan Warsa dan Mustanda (2016) yang menunjukkan hasil bahwa NPL memiliki pengaruh negatif dan signifikan terhadap ROA

\section{Pengaruh LDR terhadap ROA}

Dari hasil perhitungan yang didapat bahwa LDR tidak memiliki pengaruh yang signifikan terhadap ROA. Hal ini ditunjukkan oleh pengolahan data SPSS dengan memperoleh $\mathrm{t}$ hitung sebesar 0,278 dan nilai signifikan sebesar 0,782. Dari hasil perhitungan ini maka hipotesis keempat yang menyatakan bahwa BOPO memiliki pengaruh yang signifikan terhadap profitabilitas bank yang diproksikan dengan ROA ditolak. Standar yang digunakan Bank Indonesia untuk rasio Loan to Deposit Ratio (LDR) adalah 80\% hingga 110\%. Jika angka rasio LDR suatu bank berada pada angka di bawah $80 \%$ (misalkan 70\%), maka dapat disimpulkan bahwa bank tersebut hanya dapat menyalurkan sebesar $70 \%$ dari seluruh dana yang berhasil dihimpun. Karena fungsi utama dari bank adalah sebagai intermediasi (perantara) antara pihak yang kelebihan dana dengan pihak yang kekurangan dana, maka dengan rasio LDR 70\% berarti 30\% dari seluruh dana yang dihimpun tidak tersalurkan kepada pihak yang membutuhkan, sehingga dapat dikatakan bahwa bank tersebut tidak menjalankan fungsinya dengan baik. Tidak berpengaruhnya LDR terhadap ROA kemungkinan diakibatkan oleh pendapatan BPR tidak hanya dari pendapatan dari bunga pinjaman yang diberikan kepada debitur tetapi juga dihasilkan dari pendapatan berbasis komisi seperti asuransi dan investasi. Hasil penelitian ini didukung oleh penelitian yang dilakukan oleh Harianto (2017) dan Lemiyana (2016), Asy'ari (2016) dan Siti Sintiya (2018) yang menunjukkan hasil bahwa NPL memiliki pengaruh negatif dan signifikan terhadap ROA.

\section{Simpulan}

Berdasarkan hasil analisis data yang telah dilakukan maka dapat ditarik kesimpulan bahwa hanya variabel NPL yang berpengaruh terhadap ROA sedangkan variabel CAR, BOPO dan LDR tidak berpengaruh. Penelitian ini memiliki keterbatasan. Pertama, kemampuan model dalam menerangkan variabel independen hanya sebesar $56,1 \%$ artinya ROA masih dapat dijelaskan oleh faktor-faktor lain diluar variabel dalam penelitian ini, sehinggan penelitian yang telah dilakukan kurang mampu mencerminkan kinerja keuangan Bank Perkreditan Rakyat di kota Palembang periode 2013-2018.

Berdasarkan kesimpulan atas hasil penelitian mengenai pengaruh CAR, BOPO, NPL dan LDR terhadap ROA, maka saran yang bisa diajukan peneliti sebagai berikut :

1. Perlunya mengambil kebijakan agar kinerja dapat ditingkatkan dengan menerapkan Manajemen Resiko secara konsisten dan konsekuen agar bisa menekan tingginya tingkat Non Performing Loan (NPL), Misal lebih jeli 


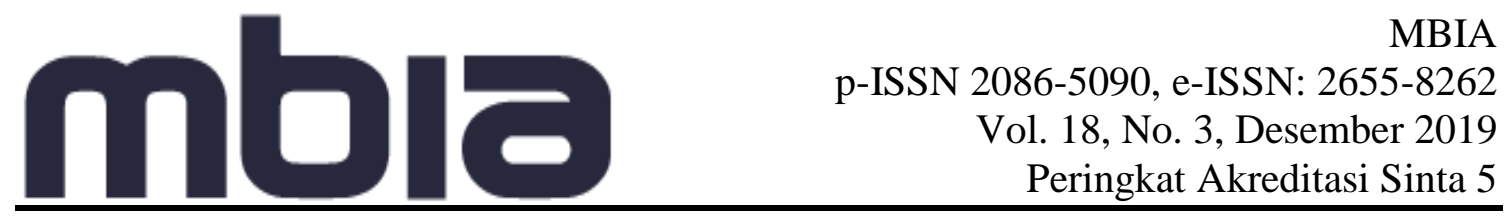

menyalurkan kredit kepada nasabah, memantau secara benar di lapangan tentang penggunaan kredit, melakukan pengecekan tentang kondisi sebenarnya calon nasabah di lapangan dan memperhitungkan cash flow dari kredit yang disalurkan.

2. Bank lebih selektif dalam mengeluarkan biaya operasional BOPO agar ROA meningkat.

3. Pihak Bank sebaiknya mempertahankan CAR agar tetap diatas $8 \%$ sesuai peraturan BI. Selain menjaga kepercayaan masyarakat juga akan menjaga kesehatan bank.

4. Penanganan secara khusus terhadap kredit yang bermasalah agar bisa meningkatkan perolehan laba.

5. Penambahan produk baru juga penting karena dapat memberikan kontribusi laba.

6. Perlunya pelatihan untuk para analis secara menyeluruh agar bisa memahami dan menjalankan tugas tugas dalam perbankan sesuai dengan aturan dan kondisi yang sedang terjadi.

\section{Daftar Pustaka}

Almazari, Ahmad. 2014. Impact of Internal factors on Bank ProfitabilityComparative Study between Saudi Arabia and Jordan, Journal of AppliedFinance \& Banking, vol 4, no 1,2014, 125-140 ISSN: 1792-6599.

Asy'ari, Abul Hasan. 2016. "Analisis pengaruh Capital Adequacy Ratio, Financing To Deposit Ratio, Non Performance Financing dan Beban Operasi Terhadap Pendapatan Operasi Terhadap Return On Asset Bank Umum Syariah Devisa di Indonesia”. Jurnal Ilmiah Ekonomi Bisnis Vol.2 No. 3 November 2016 Hal 420-426.

Azwir,Yacub. 2006. Analisis Pengaruh Kecukupan Modal,Efisiensi, Likuiditas, Npl, Dan PPAP Terhadap Roa Bank. Tesis. Magister Manajemen, Un.versitas Diponegoro Semarang.

Bilian Fenandi \& Purwanto.2015.Analisis Pengaruh CAR,NIM,BOPO dan LDR terhadap Profitabilitas Bank Persero. Faculty of Business,President University,Bekasi, Indonesia.

Dendawijaya, Lukman. 2009. Manajemen Perbankan. Bogor. Penerbit Ghalia Indonesia.

Edhi Satriyo W\&Muhammad Sayichu.2013.Analisis Pengaruh Suku Bunga, Inflasi,CAR.BOPO,NPF terhadap Profitabilitas Bank Syariah. Diponegoro Journal Of Management Vol.2 Nomor 2, Tahun 2013,Hal 1-10.ISSN:2337-3792.

Erna Sudarmawanti \& Joko Pramono.2017. Analisis Pengaruh CAR,NPL, BOPO,NIM dan LDR Terhadap ROA (Studi Kasus pada Bank Perkreditan Rakyat di Salatiga yang terdaftar di Otoritas Jasa Keuangan Tahun 2011-2015). Jurnal Among Makarti,Vol.10 No.19 Juli 2017.

Eng, Tan Sau. 2013. "Pengaruh NIM, BOPO,LDR, NPL \& CAR trhadap ROA Bank Internasional dan Bank Nasional Go Public Periode 2007-2011". Jurnal Dinamika Manajemen, Vol.1 No.3 Hal. 164.

Fajari Slamet\&Sunarto.2017.Pengaruh CAR,LDR,NPL,BOPO terhadap Profitabilitas Bank (Studi Kasus Perusahaan Perbankan yang tercatat di Bursa Efek Indonesia Periode tahun 2011-2015. Prosiding Seminar Nasional Multidisiplin Ilmu Unisbank ke-3 2017.ISBN:0-789-7936-499-93. 


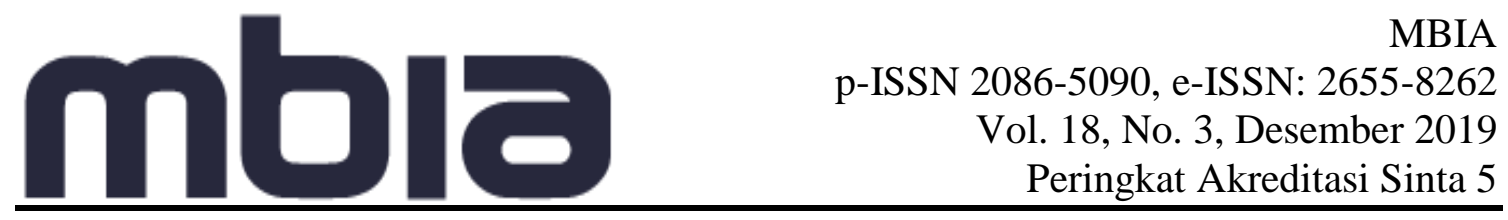

Harianto, Syawal. 2017. "Rasio Keuangan dan Pengaruhnya Terhadap Profitabilitas pada Bank Pembiayaan Rakyat Syariah di Indonesia ". Jurnal Bisnis dan Manajemen. Vol.7 (1). Hlm.41.

Ikatan Bankir Indonesia (IBI). 2016. Supervisi Manajemen Resiko Bank. Edisi Pertama, Penerbit Gramedia Pustaka. Jakarta.

Ismail. 2014. Akuntansi Bank : Teori dan Aplikasi dalam Rupiah Edisi Revisi. Jakarta:Kencana Prenadamedia Group.

Kristianti, Rina Adi dan Yovin. 2016. Factors Affecting Bank Performance: Cases of Top 10 Biggest Government and Private Banks in Indonesia in 2004 - 2013. Review of Integratif Business and Economics Research, 5(4):371- 378

Lemiyana dan Erdah Listriani. 2016. "Pengaruh NPF, FDR, BOPO Terhadap ROA pada Bank Umum Syariah". I=Economic Vol. 2 No. 1 juli 2016 hlm 48.

Margaretha, Farah \& Pinkan, Z.M. 2013. Faktor-faktor yang mempengaruhi Kinerja Keuangan Perbankan Indonesia. Jurnal Bisnis dan Akuntansi Vol. 15, No.2. ISSN: 1410-9875.

Mawardi,Wisnu.2004. Analisis faktor yang mempengaruhi Kinerja Bank Umum di Indonesia. Tesis. Magister Manajemen, Universitas Diponegoro Semarang.

Pratiwi, Luh Putu Sukma Wahyuni., dan Ni Luh Putu Wiagustini. 2015. Pengaruh CAR, BOPO, NPL Dan LDR Terhadap Profitabilitas. E-Jurnal Manajemen Unud, 5(4):2137-2166.

Purwoko, Didik \& Sudiyatno, Bambang. 2013. Faktor-faktor yang Mempengaruhi Kinerja Bank. Studi Empirik pada industri Perbankan di Bursa efak Indonesia. Jurnal Dinamika Keuangan dan Perbankan. Hal 25-39 ISSN: 1412-3126.

Riadi, Edi. 2016. Statistik Penelitian, Analisis Manual dan IBM SPSS Edisi Pertama. Penerbit Andi Obset. Yogyakarta.

Sabir Muhammad,M.Ali \&Abdul Hamid.2012.Pengaruh Rasio Kesehatan Bank Terhadap Kinerja Keuangan Bank Umum Syariah dan Bank Konvensional di Indonesia. Jurnal Analisis,Juni 2012,Vol.1 No.1 Hal:79-86.ISSN: 2303-1001.

Siti Sintiya.2018. Analisis Pengaruh BOPO,FDR dan CAR Terhadap Profitabilitas Bank Umum Syariah Periode 2012-2016 (Studi Kasus pada Bank Umum Syariah di Indonesia Periode 2012-2016). Skripsi. (IAIN) Salatiga.

Sudiyatno, Bambang. 2010. Analisis Pengaruh Dana Pihak Ketiga, BOPO, CAR dan LDR Terhadap Kinerja Keuangan pada Sektor Perbankan yang Go Public di Bursa Efek Indonesia. Jurnal Dinamika Keuangan dan Perbankan, ISSN: 1979-1878.

Taswan. 2010. Manajemen Perbankan. Konsep, Teknik dan Aplikasi. Yogyakarta. Penerbit UPP STIM YKPN.

Undartik Sri.2015. Analisis Profitabilitas Bank Umum Go Public di Indonesia Sebelum dan Setelah Krisis. Faktor Internal dan Eksternal. Jurnal Ekonomi Kwantitatif Terapan. Vol.8 No.2 ISSN:2301-8968.

Warsa, Ni Made Inten Uthami Putri., dan I Ketut Mustanda. 2016. Pengaruh CAR, LDR Dan NPL Terhadap ROA Pada Sektor Perbankan Di Bursa Efek Indonesia. E-Jurnal Manajemen Unud, 5(5):2842 - 2870

Yonira Bagiani. 2014. Pengaruh CAR,NPL,BOPO dan LDR terhadap Profitabilitas Bank (ROA) pada Perusahaan Perbankan yang Terdaftar di Bursa Efek Indonesia Periode 2009-2012. Skripsi. Universitas Negeri Yogyakarta. 
Yuliani. 2007. Hubungan Efisiensi Operasional Dengan Kinerja Profitabilitas Pada Sektor Perbankan Yang Go Publik Di Bursa Efek Jakarta. Jurnal Manajemen \& Bisnis Sriwijaya Vol. 5 No 10 Desember 2007.

Yusriani.2018. Pengaruh CAR,NPL, BOPO dan LDR terhadap Profitabilitas Pada Bank Umum Milik Negara Persero di Bursa Efek Indonesia,Jurnal Riset Edisi XXV Vol.04 No.002 2018.

Zulfikar, Taufik.2014. Pengaruh CAR,LDR,NPL,BOPO dan NIM Terhadap Kinerja Profitabilitas (ROA) Bank Perkreditan Rakyat Indonesia. Jurnal Unpar.ac.id/index.php/unpar graduate/article/view/850.Vol 1 No.2.

\section{Copyright Disclaimer}

Copyright for this article is retained by the author(s), with first publication rights granted to the journal. 